Article

\title{
The Dynamic Yield Response Factor of Alfalfa Improves the Accuracy of Dual Crop Coefficient Approach under Water and Salt Stress
}

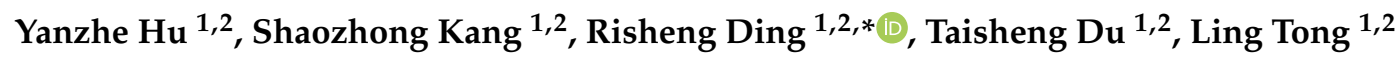 \\ and Sien $\mathrm{Li}^{1,2}$ \\ 1 Center for Agricultural Water Research in China, China Agricultural University, Beijing 100083, China \\ 2 Wuwei Experimental Station for Efficient Water Use in Agriculture, Ministry of Agriculture and Rural \\ Affairs, Wuwei 733000, China \\ * Correspondence: dingrsh@cau.edu.cn
}

Received: 5 April 2020; Accepted: 23 April 2020; Published: 25 April 2020

check for updates

\begin{abstract}
The accurate quantification of crop water use or evapotranspiration $(E T)$ under water and salt stress is needed for efficient water management and precision irrigation in water scarce regions. However, few studies were examined on alfalfa water use and its components under water and salt stress. We carried out two field experiments to quantify alfalfa water use through setting up different water and salt gradients, including two irrigation levels (full and deficit irrigation) and four soil salinity levels $(0,2 \%, 4 \%$ and $6 \%$ salt of mass ratio) in an arid region of Northwest China. Electrical conductivity of soil saturation extract $\left(E C_{e}\right)$, soil water content $(S W C)$, leaf area index $(L A I)$ and soil evaporation $(E)$ were measured. The SIMDualKc model, which uses the FAO56 dual $\mathrm{K}_{\mathrm{c}}$ approach, was calibrated and validated using measured SWC and E. Model results show a good agreement between observed and simulated SWC and $E$ without stress. The depletion fraction for no stress $(p)$ and the percent yield reduction per unit increase in soil salinity $(b)$ were 0.50 and $6.0 \% /\left(\mathrm{dS} \mathrm{m}^{-1}\right)$, respectively, slightly lower than those of FAO-56 $\left(0.55\right.$ and $\left.7.3 \% /\left(\mathrm{dS} \mathrm{m}^{-1}\right)\right)$. The difference indicates that alfalfa has a lower capacity of water use but a greater tolerance to salt stress after soil salinity reached its sensitivity threshold in the arid region. The model performed a reduced accuracy under water and salt stress and the differences tended to increase as stress increased, which was partly attributed to constant yield response factor $\left(K_{y}\right)$ under different soil water and salt stress. The key parameter $K_{y}$ dynamically increased with the increased degree of stress. Compared to constant $K_{y}$, the simulations of $S W C$ and $E$ showed improved accuracy with dynamic $K_{y}$. These results suggested that the response and acclimation of alfalfa to stress might be incorporated into the dual $\mathrm{K}_{\mathrm{c}}$ model through the diversity of $K_{y}$.
\end{abstract}

Keywords: dual crop coefficient; water use; water and salt stress; yield response factor; alfalfa

\section{Introduction}

Drought and salinization, as worldwide problems, severely restrict crop productivity in arid and semi-arid areas where poor rainfall is insufficient to leach soil salts out of the root zone, and reasonable irrigation is a necessary strategy for the continuous food production of the growing population [1,2]. Accurate estimation of crop water use is the foundation of designing scientific irrigation system and improving water management. Alfalfa (Medicago sativa L.), as a forage crop with high water requirement [3,4], high water-saving potential and moderate salt sensitivity [5], is widely planted in arid region of Northwest China, and is highly dependent on irrigation. Thus, accurate estimation of alfalfa water use or evapotranspiration $(E T)$ is of great significance for developing efficient water-saving irrigation and improving water use efficiency. 
The $E T$ of alfalfa can be estimated by many methods, e.g., water balance method [3,6-8] and crop coefficient $\left(K_{c}\right)$ approach [9-11]. Specifically, the $K_{c}$ approach is relatively simple and accurate, which is obtained by the product of reference $E T\left(E T_{0}\right)$ and specific $K_{c}[12]$, and the latter is related to crop species, variety, growth stage, canopy structure and management $[5,13]$. The dual $\mathrm{K}_{\mathrm{c}}$ approach separates $E T$ into two components, transpiration $(T)$ and evaporation $(E)$, and replaces $K_{c}$ with the sum of basal crop coefficient $\left(K_{c b}\right)$ and soil evaporation coefficient $\left(K_{e}\right)$. Compared with the single $K_{\mathrm{c}}$ approach, the dual $\mathrm{K}_{\mathrm{c}}$ approach can simulate crop water use more accurately, especially when the canopy is relatively small in the early growth stage. For efficient water management, $E$ is considered as water loss that does not directly contribute to the production process, whereas $T$ is directly related to crop productivity and considered to be the more "efficient" part [14]. Therefore, it is vital to accurately estimate $E T$ and its components for improving water management efficiency, especially in arid and semi-arid areas where losses through evaporation can be considerable.

The dual $\mathrm{K}_{\mathrm{c}}$ approach has been applied to corn, wheat, soybean and other food cereal crops under full irrigation conditions, and was proved relatively accurate for estimating water use and components [15-19]. The approach is more advantageous for irrigation methods with soil surface not completely wet, such as drip irrigation [20-22], and has an improved estimation accuracy $[9,23]$. For non-optimum conditions, the effects are considered through stress coefficient $K_{s}$ [24,25]. A study showed a reduction in the performances of the dual $\mathrm{K}_{\mathrm{c}}$ approach when estimating water use of corn under water stress [26]. Yet, there are very few studies that measure the effects of water and salt stress on $K_{s}$, especially for forage crops.

A combination of two or more abiotic stresses, such as drought and salinity, results in more water use and yield loss than a single one [27]. Different from saline water irrigated soil, saline soil, which contains multiple salt ions, is often the real situation where crops can suffer from salt stress [28]. The main ions toxic to crops include $\mathrm{Na}^{+}, \mathrm{Cl}^{-}$and $\mathrm{SO}_{4}{ }^{2-}$ [29]. The response of growth and physiological traits to coupling stress of water and salt has been done on barley, corn, cotton, tomato and other crops [30-33]. In FAO-56, the stress factor of crop coefficient is incorporated by combining water stress through soil water content and salt stress through soil electrical conductivity and water-yield response factor $\left(K_{y}\right)[5,34] . K_{y}$ is a factor that describes the reduction in relative yield according to the reduction in ET. So, it is a vital parameter of calculating $K_{s}$ in dual $\mathrm{K}_{\mathrm{c}}$ approach, which is commonly supposed to be a constant under different soil water and salt stress [5]. Other studies argued that a properly selected $K_{y}$ value is also important and should adopt $K_{y}$ derived from experimental data $[15,35,36]$. However, relatively few experiments had been conducted to estimate daily alfalfa $E T$ and its components under water and salt stress using the dual $\mathrm{K}_{\mathrm{c}}$ approach and experimental $K_{y}$.

Thus, we hypothesize that the value of $K_{y}$ varies dynamically with different water and salt stress, and the performance of dual $\mathrm{K}_{\mathrm{c}}$ approach will be improved with a dynamic value of $K_{y}$ under water and salt stress. The objectives of our study were to estimate the $E T$ and components of alfalfa using the dual $\mathrm{K}_{\mathrm{c}}$ approach, and obtain a set of parameters suitable for alfalfa in arid region of Northwest China under water and salt stress conditions; and evaluate the effect of the constant and dynamic $K_{y}$ on $E T$ and its components.

\section{Materials and Methods}

\subsection{Experimental Site and Design}

The experiment was conducted at the Shiyanghe Experimental Station at China Agricultural University, located in the city of Wuwei, Gansu Province, northwest China (37 $52^{\prime} \mathrm{N}, 102^{\circ} 50^{\prime} \mathrm{E}$, at 1581 m elevation), during June 6th to September 8th, 2018 and May 11th to September 20th, 2019. The experimental site belongs to a typical cold desert climate (BWk) according to Koppen Geiger classification, where light and heat resources are abundant, with the mean annual duration of sunshine being over $3000 \mathrm{~h}$ and mean annual solar radiation is $5694 \mathrm{MJ} \mathrm{m}^{-2}$, the mean frost free days numbering 
over $150 \mathrm{~d}$, mean annual temperature of $8^{\circ} \mathrm{C}$, and an annual sum of 3550 growing degree days $\left(0^{\circ} \mathrm{C}\right.$ as base temperature). The region is short of water with an average annual precipitation of $164 \mathrm{~mm}$, mean annual pan evaporation of approximately $2000 \mathrm{~mm}$ and groundwater table below $25 \mathrm{~m}$ depth.

The experiment was carried out in non-weighing lysimeters (Figure 1), whose sides and bottom were made of concrete to prevent seepage, with an area of $6.66 \mathrm{~m}^{2}(3.33 \mathrm{~m} \times 2 \mathrm{~m})$, and a depth of 3 $\mathrm{m}$. The soil filled in was sandy loam, with an average dry bulk density of $1.5 \mathrm{~g} \mathrm{~cm}^{-3}$ and the field capacity $\left(\theta_{\mathrm{f}}\right)$ of $0.30 \mathrm{~m}^{3} \mathrm{~m}^{-3}$, the wilting point $\left(\theta_{\mathrm{wp}}\right)$ of $0.13 \mathrm{~m}^{3} \mathrm{~m}^{-3}$, and saturation water content of $0.37 \mathrm{~m}^{3} \mathrm{~m}^{-3}$ in $0-100 \mathrm{~cm}$. The basic physical properties of the soil were presented in Table S1 [37]. The experiment set up eight treatments with two irrigation amount levels in 2018, i.e., full irrigation and deficit irrigation (W1 and W2), and four soil salinity levels, i.e., 0, 2\%o, 4\%o and 6\%o salt (mass ratio) per unit soil mass in the 0-60 cm soil (S0, S2, S4 and S6), and four treatments (W1S0, W2S2, W2S4 and W2S6) in 2019, representing full irrigation with no salt stress, deficit irrigation with $2 \%$ soil salt content, deficit irrigation with $4 \%$ o soil salt content and deficit irrigation with $6 \%$ soil salt content. To minimize the boundary layer effect, alfalfa were planted around the lysimeters with a width of more than $1 \mathrm{~m}$ and with the same management.

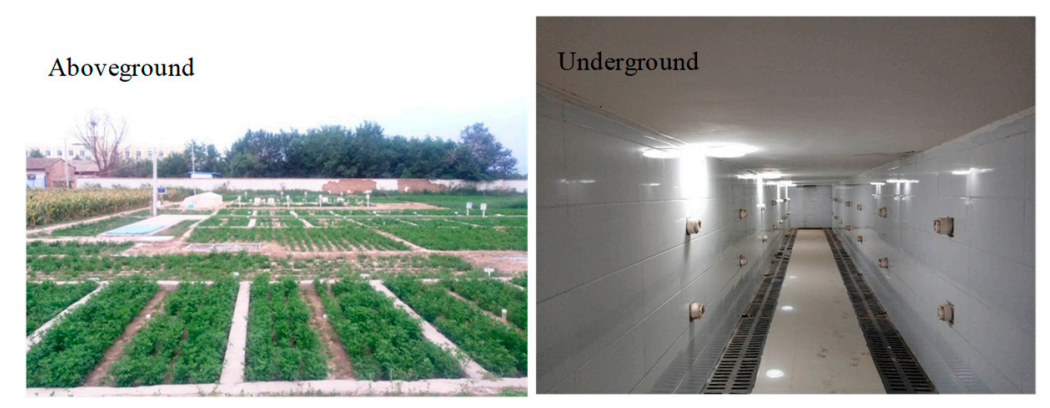

Figure 1. Lysimeters where the experiment was carried out.

Alfalfa (Golden Empress) was sown in line on 2 May 2017, with the row spacing of $25 \mathrm{~cm}$ and plant spacing of $10 \mathrm{~cm}$, respectively, and the planting density was $30 \mathrm{~kg} \mathrm{~h}^{-1}$. Unified field management had been applied before the experiment started. Full irrigation treatment (W1) was irrigated to $95-100 \% \theta_{\mathrm{f}}$ when average soil water content $(S W C)$ in $0-80 \mathrm{~cm}$ reached $65-70 \% \theta_{\mathrm{f}}$, and the irrigation amounts of deficit treatments (W2) were half of that of W1 in 2018. Irrigation amounts of deficit irrigation treatments in 2019 were applied according to the same ET proportion to W1S0 in 2018. For alleviating salt stress on crop growth, all treatments were irrigated to field capacity on June 9 and 17 in 2018. The detailed irrigation scheduling was showed in Table S2 and Table S3. The salt used consisted of mixed $\mathrm{NaCl}, \mathrm{MgSO}_{4}$ and $\mathrm{CaSO}_{4}$ at a mass ratio of 2:2:1, according to local groundwater chemical composition [38], and were added into the soil by saline water irrigation before treatments. Drip irrigation was used in the experiment, with a discharge of $3 \mathrm{~L} / \mathrm{h}$ and emitter interval of $30 \mathrm{~cm}$.

\subsection{Field Measurements}

Meteorological data during the experiment were collected every 15 minutes by an automatic weather station (Hobo, Onset Computer Corp., Bourne, MA, USA) about $100 \mathrm{~m}$ away from the experimental plots. Daily precipitation and $E T_{0}$ were shown in Figure 2. Daily $E T_{0}$ was calculated by the FAO-56 Penman-Monteith formula [5].

Plant height was measured manually every 5-7 d, and leaf area index ( $L A I)$ every $4-5 \mathrm{~d}$ by a plant canopy analyzer (LAI-2200C, LI-COR Corporate, Lincoln, NE, USA). The whole growth period of alfalfa was divided into initial growth stage, rapid development stage, mid-season stage and late-season stage (Table S4 and Table S5). Alfalfa was cut three and four times when entering the initial flowering period on July 3, August 4 and September 8 in 2018 and June 17, July 17, August 16 and September 20 in 2019 , respectively. The maximum root depth, plant height and LAI of each treatment were shown in Table S6 and Table S7. 

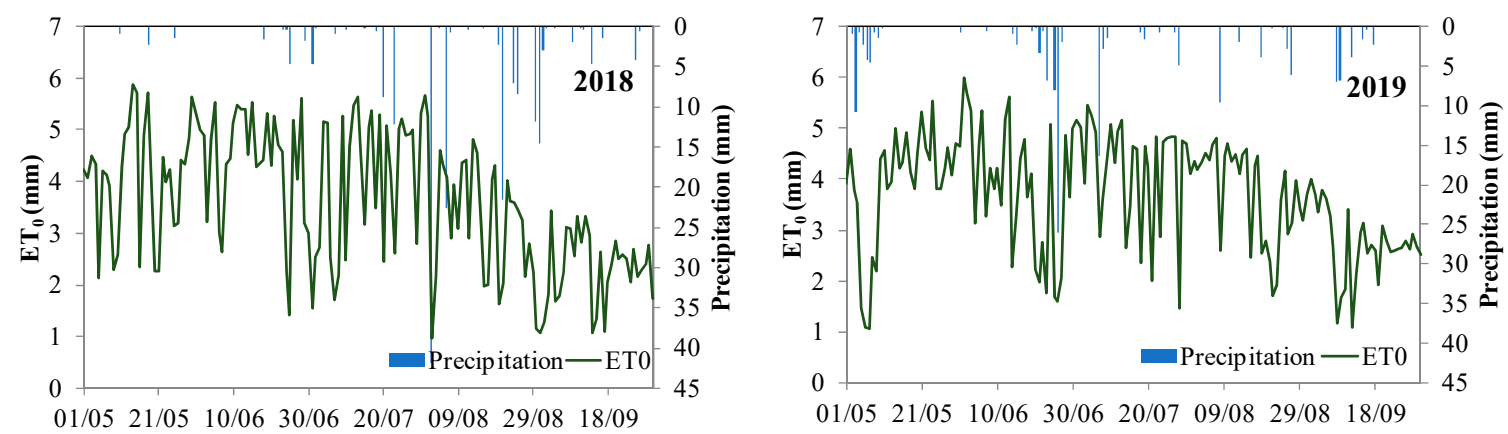

Figure 2. Daily reference evapotranspiration $\left(E T_{0}\right)$ and precipitation during the whole growth period of alfalfa.

The SWC was measured using the gravimetric method. The soil samples were taken every $5-7 \mathrm{~d}$ using soil auger during the growth period of alfalfa at the depth of $0-10,10-20,20-40,40-60,60-80$ and $80-100 \mathrm{~cm}$, and the same texture of soil was quickly backfilled. The soil salt samples took at the beginning and the end of cuttings were air-dried, ground and passed through $1 \mathrm{~mm}$ sieve. Soil leachate was prepared at soil-to-water ratio of 1:5. Electrical conductivity, $E C_{1: 5}$ was measured using an electrical conductivity meter (S230, Mettler-Toledo International Inc., Switzerland), and then converted to the electrical conductivity of saturated paste $\left(E C_{e}\right)$ with the following equation [39]:

$$
E C_{\mathrm{e}}=12.04 \times 10^{-3} E C_{1: 5}-1.35\left(R^{2}=0.9474\right)
$$

Daily $E$ was measured by microlysimeter made from PVC tubes with a diameter of $10 \mathrm{~cm}$ and height of $20 \mathrm{~cm}$, with bottom wrapped with filter paper and gauzes to keep water connection with outside soil [19]. Daily $E$ at each microlysimeter was obtained as the difference between the weights measured by an electronic scale with the precision of $0.1 \mathrm{~g}$ at 19:00 pm, except on rainy or irrigation days.

\subsection{The Dual Kc Approach}

We used the SIMDualKc model, which is based on dual crop coefficient approach, to estimate daily alfalfa $E T$. According to the dual $\mathrm{K}_{\mathrm{c}}$ approach in the FAO-56 [5,25], the actual daily ET of alfalfa was calculated as follows:

$$
E T=\left(K_{s} K_{c b}+K_{e}\right) E T_{0}
$$

where $K_{s}$ is the stress coefficient, which combines water stress $\left(K_{s w}\right)$ and salt stress $\left(K_{s s}\right) . K_{c b}$ is the basal crop coefficient, and for specific adjustment in climates where $\mathrm{RH}_{\min }$ differs from $45 \%$ or the wind speed is not $2 \mathrm{~m} \mathrm{~s}^{-1}$, the mid-season $K_{c b \text { mid }}$ and late-season $K_{c b}$ end values larger than 0.45 must be adjusted [5,25], and $K_{e}$ is the soil evaporation coefficient. The dual $\mathrm{K}_{\mathrm{c}}$ approach simulates crop water use at a daily step, and its basic parameters include soil, irrigation, climate and crop parameters, and drainage and salinity parameters. When only the $S W C$ is constraining crop transpiration, $K_{s w}$ is computed as:

$$
K_{s w}=\frac{T A W-D_{r, i}}{T A W-R A W}=\frac{T A W-D_{r, i}}{(1-p) T A W}
$$

where TAW and $R A W$ are respectively the total and readily available soil water relative to the rooting depth (mm), with $R A W=p$ TAW ( $p$ is the depletion fraction for no stress), and $D_{r, i}$ is the soil water depleted from the root zone at the end of day $i(\mathrm{~mm})$. When the salt is only constraining crop transpiration, i.e., soil salinity exceeds the crop specific value of $E C_{e}$ when the crop starts to be stressed due to its sensitivity to salinity $\left(E C_{e}>E C_{e}\right.$ threshold $)$ while water depletion less than $R A W\left(D_{r}<R A W\right)$, $K_{s s}$ is computed as:

$$
K_{s S}=1-\frac{b}{K_{y} 100}\left(E C_{e}-E C_{\text {ethreshold }}\right)
$$


where $b$ is the percent yield reduction per unit increase in $E C_{e}\left(\% / \mathrm{dS} \mathrm{m}^{-1}\right)$, and $K_{y}$ is the dimensionless water-yield response factor. $K_{y}$ is obtained by model calibration or calculated through the linear relationship of relative reduction of yield and ET.

$$
\left(1-\frac{Y_{a}}{Y_{m}}\right)=K_{\mathrm{y}}\left(1-\frac{E T_{a d j}}{E T_{\mathrm{m}}}\right)
$$

where $Y_{a}$ is the actual yield $\left(\mathrm{kg} \mathrm{h}^{-1}\right), Y_{m}$ is the maximum crop yield $\left(\mathrm{kg} \mathrm{ha}^{-1}\right), E T_{a d j}$ is the adjusted (actual) crop $E T(\mathrm{~mm})$ and $E T_{m}$ is crop ET with no stress $(\mathrm{mm})$.

When water and salt stress coexist $\left(E C_{e}>E C_{e}\right.$ threshold, $\left.D_{r}>R A W\right), K_{s}$ is computed as:

$$
K_{s}=\left(1-\frac{b}{K_{y} 100}\left(E C_{e}-E C_{\text {ethreshold }}\right)\right)\left(\frac{T A W-D_{r, i}}{T A W-R A W}\right)
$$

where TAW and RAW are supposed to be constant as soil salt increases, which is probably unreasonable for some crops [5]. Rosa et al. [25] indicated that $\theta_{\mathrm{wp}}$ would increase while $p$ decrease slightly, and further adjustment is needed to recompute $T A W_{\text {salt }}$ and $R A W_{\text {salt }}$ under salt stress.

\subsection{Model Calibration and Validation}

We calibrated all key parameters under water and salt stress and emboldened values different from initial ones. Parameter calibration was carried out through adjusting soil evaporation (depth of the soil evaporation layer $\left(Z_{e}\right)$, total evaporable water $(T E W)$ and readily evaporable water $(R E W)$ ), crop $\left(K_{c b}, p\right.$ and $\left.K_{y}\right)$, drainage (empirical parameters of the deep percolation parametric function $\left(a_{p}\right.$ and $\left.b_{p}\right)$ ) and salinity $\left(E C_{e}\right.$ threshold and $b$ ) parameters to minimize the difference between the simulated and observed SWC in the root zone. Based on the recommended parameter values in FAO-56, trial and error adjustments were first done with the $K_{c b}, p$ and $K_{y}$, in order to minimize the differences between observed and simulated TAW. Then trial and error was further applied to $Z_{e}, T E W$ and $R E W$. The $E C_{e}$ threshold and $b$ were also adjusted using recommended values in the FAO-56 $\left(2.0 \mathrm{dS} \mathrm{m}^{-1}\right.$ and $7.3 \% /(\mathrm{dS}$ $\left.\mathrm{m}^{-1}\right)$ ) as initial values until differences of simulations and measurements were minimized and become stable from an iteration to the next [40]. Four treatments in 2018 (W1S0, W2S6, W1S4 and W2S2) were used for calibration, while the remaining treatments of 2018 (W2S0, W1S6, W2S4 and W1S2) and all the treatments of 2019 were used for validation. W1 and W2 indicated full irrigation and deficit irrigation, and S0, S2, S4 and S6 indicated $0 \%, 2 \%, 4 \%$ and $6 \%$ mass ratio of salt per unit soil mass in the depth of $0-60 \mathrm{~cm}$. In order to assess the effect of $K_{y}$ on simulations, $K_{y}$ for different treatments was recomputed using simulated ET and actual yield in 2018 by Equation (5), and then used in 2019 simulations.

A series of indicators were used to evaluate the simulation, including linear regression coefficient $\left(b\right.$, non-dimensional) and coefficient of determination $\left(R^{2}\right.$, non-dimensional), with $b$ and $R^{2}$ being close to 1 indicates that the covariance is close to the variance of the observed values and most of the variation of the observed values can explained by the model. Root mean square error (RMSE, same units as $O_{i}$ ), which characterizes the variance of the errors, average absolute error $\left(A A E\right.$, same units as $\left.O_{i}\right)$, which expresses the size of estimation errors in alternative to RMSE, the Nash and Sutcliffe (1970) modeling efficiency ( $E F$, non-dimensional), which determines the relative magnitude of the residual variance compared to the measured data variance, and Willmott (1981) index of agreement $\left(d_{I A}\right.$, non-dimensional), representing the ratio between the mean square error and the "potential error" [18].

$$
b=\frac{\sum_{i=1}^{n}\left(O_{i}-\bar{O}\right)\left(S_{i}-\bar{S}\right)}{\sum_{i=1}^{n}\left(O_{i}-\bar{O}\right)^{2}}
$$




$$
\begin{gathered}
R^{2}=\left\{\frac{\sum_{i=1}^{n}\left(O_{i}-\bar{O}\right)\left(S_{i}-\bar{S}\right)}{\left[\sum_{i=1}^{n}\left(O_{i}-\bar{O}\right)^{2}\right]^{0.5}\left[\sum_{i=1}^{n}\left(S_{i}-\bar{S}\right)^{2}\right]^{0.5}}\right\}^{2} \\
R M S E=\left[\frac{\sum_{i=1}^{n}\left(S_{i}-O_{i}\right)^{2}}{n}\right]^{0.5} \\
A A E=\frac{1}{n} \sum_{i=1}^{n}\left|O_{i}-S_{i}\right| \\
E F=1.0-\frac{\sum_{i=1}^{n}\left(O_{i}-S_{i}\right)^{2}}{\sum_{i=1}^{n}\left(O_{i}-\bar{O}\right)^{2}} \\
d_{I A}=1-\frac{\sum_{i=1}^{n}\left(O_{i}-S_{i}\right)^{2}}{\sum_{i=1}^{n}\left(\left|S_{i}-\bar{O}\right|+\left|O_{i}-\bar{O}\right|\right)^{2}}
\end{gathered}
$$

where $\mathrm{n}$ was number of observed values, $O_{i}$ and $S_{i}$ were paired observed and simulated values $(\mathrm{i}=1$, $2, \ldots, \mathrm{n})$, and $\bar{O}$ and $\bar{S}$ were the average of observed and simulated values.

\section{Results and Discussion}

\subsection{Daily Crop Coefficients and ET Components}

All key parameters under water and salt stress were calibrated (Table 1). The calibrated results indicated that some parameters were relative conservative, and others were specific for different soil texture, field management or crop cultivar, which were emboldened as different from initial values. Calibrated $K_{c b}$ for alfalfa at the initial $\left(K_{c b i n i}\right)$, mid-season $\left(K_{c b m i d}\right)$ and late $\left(K_{c b e n d}\right)$ stages, representing the alfalfa $K_{c b}$ immediately following cutting, at full cover and immediately before cutting respectively, were in agreement with those proposed by the FAO-56 (Table 1). The $p$ was adjusted to 0.50 from 0.55 , indicating a reduced capacity of alfalfa water use, which is related to crop cultivar, soil texture and local environment [41]. Specifically, $p$ is also a function of the evaporation power of the atmosphere. For hot dry weather conditions, where $E T$ is high, $p$ is $10-25 \%$ less than the value proposed by the FAO-56, and the stress could start to occur when the soil is still relatively wet $[5,42]$. The parameters for estimating deep percolation, $a_{p}$ and $b_{p}$, as described by Liu et al. [43], were adjusted to $310 \mathrm{~mm}$ and -0.065 , respectively using the trial and error approach. As an important parameter estimating $K_{s s}, K_{y}$ was 1.2. The $E C_{e \text { threshold }}$ was the same as the FAO- 56 value, with $2.0 \mathrm{dS} \mathrm{m}^{-1}$. The $b$ was $6.0 \% /\left(\mathrm{dS} \mathrm{m}^{-1}\right)$, slightly being lower than $7.3 \% /\left(\mathrm{dS} \mathrm{m}^{-1}\right)$ in the FAO-56, indicating that the sensitivity to salinity of alfalfa in this study is slightly lower than that in the FAO-56 when $E C_{e}>E C_{e}$ threshold, which might be associated with the varieties of alfalfa [44].

The calibrated and validated SWC and measurements in 2018 were presented in Figure 3. The goodness of fit indicators of SWC simulations were presented in Table 2. The regression coefficient $b$ ranged from 0.89 to 1.02 , and the $R^{2}$ from 0.70 to 0.91 , meaning that the simulated SWC adhered well to the observations, and most of the variance could be explained by the model; the RMSE of all treatments was smaller than $0.02 \mathrm{~m}^{3} \mathrm{~m}^{-3}$, and $A A E$ was lower than $0.12 \mathrm{~m}^{3} \mathrm{~m}^{-3}$, indicating that the variability and average of errors was acceptable. The $E F$ varied from 0.61 to 0.89 , and $d_{I A}$ of all treatments were above 0.90. Overall, these results showed that the SIMDualKc model was able to explain and predict the variation of $S W C$ in the root zone under water and salt stress (soil salinity content $\leq 6 \%$ o), thus $E T$. 
Table 1. Initial and calibrated values for the crop and soil parameters in the SIMDualKc model.

\begin{tabular}{|c|c|c|}
\hline Parameters. & Initial Values & Calibrated \\
\hline \multicolumn{3}{|l|}{ Crop coefficients } \\
\hline$K_{c b i n i}$ & 0.3 & 0.3 \\
\hline$K_{c b \text { mid }}$ & 1.15 & 1.15 \\
\hline$K_{c b \text { end }}$ & 1.1 & 1.1 \\
\hline$K_{y}$ & 1.1 & 1.2 \\
\hline$p$ & 0.55 & 0.50 \\
\hline \multicolumn{3}{|l|}{ Soil evaporation } \\
\hline$R E W(\mathrm{~mm})$ & $6-10$ & 10 \\
\hline TEW (mm) & $15-30$ & 30 \\
\hline$Z_{e}(\mathrm{~m})$ & $0.1-0.15$ & 0.12 \\
\hline \multicolumn{3}{|l|}{ Deep percolation } \\
\hline$a_{p}(\mathrm{~mm})$ & 360 & 310 \\
\hline$b_{p}$ & -0.0173 & -0.065 \\
\hline Salinity & & \\
\hline$b\left(\% /\left(\mathrm{dS} \mathrm{m}^{-1}\right)\right)$ & 7.3 & 6.0 \\
\hline$E C_{e}$ threshold $\left(\mathrm{dS} \mathrm{m}^{-1}\right)$ & 2.0 & 2.0 \\
\hline
\end{tabular}

$K_{c b}$, alfalfa basal crop coefficient at the initial (ini), mid-season (mid) and late-season (end) stages; $K_{y}$, the dimensionless water-yield response factor; $p$, the soil-water depletion fraction for no stress; REW and TEW, readily and total evaporable water; $Z_{e}$, the depth of the soil evaporation layer; $a_{p}$ and $b_{p}$, empirical parameters of the deep percolation parametric function; $b$, the percent yield reduction per unit increase in electrical conductivity of the soil saturate extract $\left(E C_{e}\right)$; and $E C_{e}$ threshold, crop specific threshold of $E C_{e}$. The emboldened values are calibrated parameters different from initial ones.
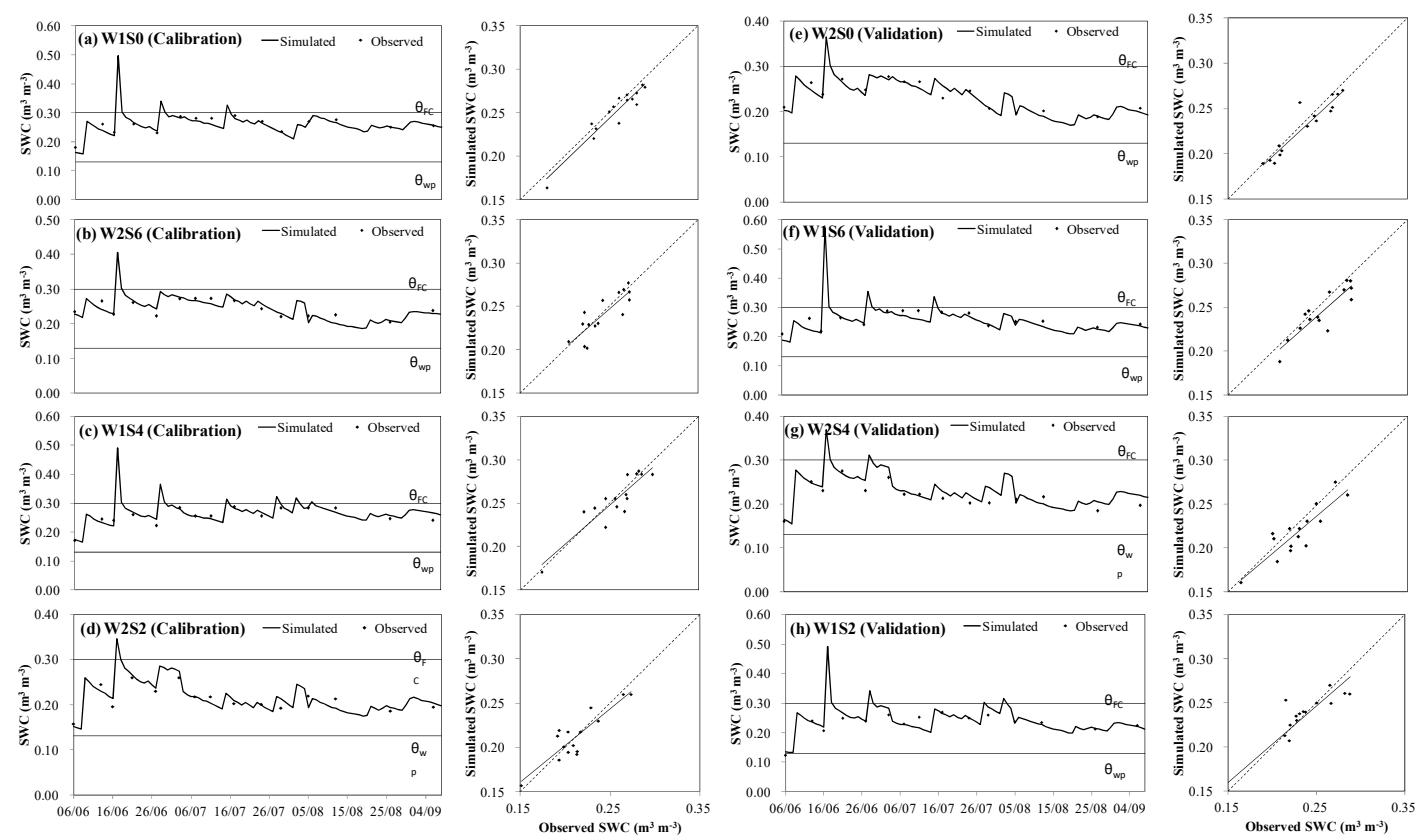

Figure 3. Simulated and observed soil water content (SWC) during the whole growth period of alfalfa in 2018: (a) W1S0, (b) W2S6, (c) W1S4 and (d) W2S2 for calibration; (e) W2S0, (f) W1S6, (g) W2S4 and (h) W1S2 for validation. On the right panel the corresponding regressions forced to the origin were shown. W1 and W2 indicated full irrigation and deficit irrigation. S0, S2, S4 and S6 indicated 0\%, 2\%o, $4 \%$ and $6 \%$ mass ratio of salt per unit soil mass in the depth of $0-60 \mathrm{~cm}$. The same as below.

Seasonal variations of $K_{c b}$, adjust $K_{c b}\left(K_{c b a d j}\right)$, and $K_{e}$ in 2018 were shown on the left panel, and the simulated $E, T$ and observed $E$ ( $n=44$ for each treatment) on the right panel in Figure 4 . The $K_{c b}$ mid and $K_{c b}$ end have been adjusted for climate and growth regimes, resulting in lower values than those presented in Table 1 [5]. The $K_{e}$ values for alfalfa of each cutting was high during the initial period, and declined during the mid-season period when ground cover was high and energy available at soil 
surface for evaporation was less. The $K_{e}$ increased after irrigation or precipitation, and the fluctuation in treatments under stress was larger (Figure 4).

Table 2. Indicators of goodness of fit of soil water content (SWC) related to the SIMDualKc model calibration and validation for alfalfa.

\begin{tabular}{cccccccc}
\hline Year & Treatments & $\boldsymbol{b}$ & $\boldsymbol{R}^{\mathbf{2}}$ & $\boldsymbol{R M S E}\left(\mathbf{m}^{\mathbf{3}} \mathbf{~ m}^{-\mathbf{3}}\right)$ & $\boldsymbol{A A E}\left(\mathbf{m}^{\mathbf{3}} \mathbf{~ m}^{-\mathbf{3}}\right)$ & $\boldsymbol{E} \boldsymbol{F}$ & $\boldsymbol{d}_{\boldsymbol{I A}}$ \\
\hline \multirow{2}{*}{2018} & W1S0 & 1.00 & 0.91 & 0.011 & 0.009 & 0.84 & 0.96 \\
& W2S0 & 0.92 & 0.89 & 0.011 & 0.009 & 0.86 & 0.96 \\
& W1S2 & 0.94 & 0.82 & 0.015 & 0.115 & 0.80 & 0.95 \\
& W2S2 & 0.94 & 0.78 & 0.014 & 0.012 & 0.74 & 0.94 \\
& W1S4 & 0.91 & 0.82 & 0.013 & 0.011 & 0.80 & 0.95 \\
& W2S4 & 0.89 & 0.77 & 0.017 & 0.014 & 0.63 & 0.91 \\
2019 & W1S6 & 0.90 & 0.79 & 0.016 & 0.012 & 0.62 & 0.91 \\
& W2S6 & 0.89 & 0.70 & 0.013 & 0.011 & 0.64 & 0.91 \\
& W1S0 & 1.02 & 0.91 & 0.010 & 0.008 & 0.89 & 0.97 \\
& W2S2 & 0.94 & 0.81 & 0.014 & 0.012 & 0.78 & 0.95 \\
& W2S4 & 0.93 & 0.76 & 0.016 & 0.012 & 0.69 & 0.92 \\
& W2S6 & 0.91 & 0.72 & 0.020 & 0.016 & 0.61 & 0.90 \\
& W2S2 & 0.94 & 0.82 & 0.014 & 0.012 & 0.79 & 0.95 \\
& W2S4 & 0.94 & 0.82 & 0.013 & 0.011 & 0.77 & 0.94 \\
& W2S6 & 0.92 & 0.83 & 0.013 & 0.010 & 0.82 & 0.95 \\
\hline
\end{tabular}

$b$, linear regression coefficient; $R^{2}$, coefficient of determination; $R M S E$, root mean square error; $A A E$, average absolute error; $E F$, the Nash and Sutcliffe modeling efficiency and $d_{I A}$, Willmott index of agreement. Indicators of year in $2019^{*}$ were recomputed using dynamic yield response factor $\left(K_{y}\right)$.

Alfalfa $K_{c}$ was closely related to the growing years, environment and planting pattern. As perennial herbage with a general life span of 5-7 years, alfalfa growth rate is slow in the first year, reaches its peak in the second to the fourth year, and declines year by year after the fifth year [45]. The growth rate and vitality also decrease year by year [3,8]. It has been three years since alfalfa was sown in 2017, and the $K_{c b}$ was 0.3 in initial stage, 1.15 in mid-season stage and 1.1 in late-season stage, respectively, which was consistent with the proposed value of FAO-56; and the annual average $K_{c}$ of 2018 and 2019 were 1.09 and 1.08, respectively, indicating a similar growth state. In the same region with this study, the $K_{c}$ of alfalfa in the 2nd and 3rd year under subsurface drip irrigation were 1.03 and 0.84 [46], while 1.13 and 1.31 under sprinkler irrigation in the same period, respectively [7]. In arid Northern Australia, the $K_{c}$ of alfalfa were 1.04 and 0.97 during two consecutive years [47]. These studies were similar to the results of our study. A slightly higher $K_{c b}$ mid of 1.22 was found in a previous study [11], which might be attributed to higher planting density of $43.5 \mathrm{~kg} \mathrm{~h}^{-1}$ [48].

The goodness of fit indicators of $E$ simulation are presented in Table 3. The variation trend of the simulated daily $E$ and measurements was consistent, even not as good as the SWC, with the $R^{2}$ above 0.75 and $\mathrm{b}$ above 0.90 . Although the RMSE and $A A E$ were relative larger and $E F$ and $d_{I A}$ lower, overall simulations of $E$ were acceptable considering the complexity of the influencing factors. The simulated values in this study tended to underestimate, which were similar with previous studies $[16,18,19]$. On the other side, measurements might be overestimated, for (a) water extraction by roots was excluded from the microlysimeters, resulting in higher soil water content in the microlysimeters than in the surrounding area, hence making that microlysimeters measurements are likely to overestimate soil evaporation; (b) due to the gap between the inner wall and the outer wall of microlysimeters, the actual evaporation of soil inside could be affected by the thermal effect. Wei et al. [16] noticed that model underestimations occurred when the crop was well developed, i.e., the fraction of ground cover was high and soil evaporation was low, and root extraction from the upper soil layer was higher. Therefore, the soil water extraction from the evaporation soil layer is larger when roots are active compared with that in microlysimeters, as the latter's extraction due to soil evaporation only, which was in agreement to our result. 

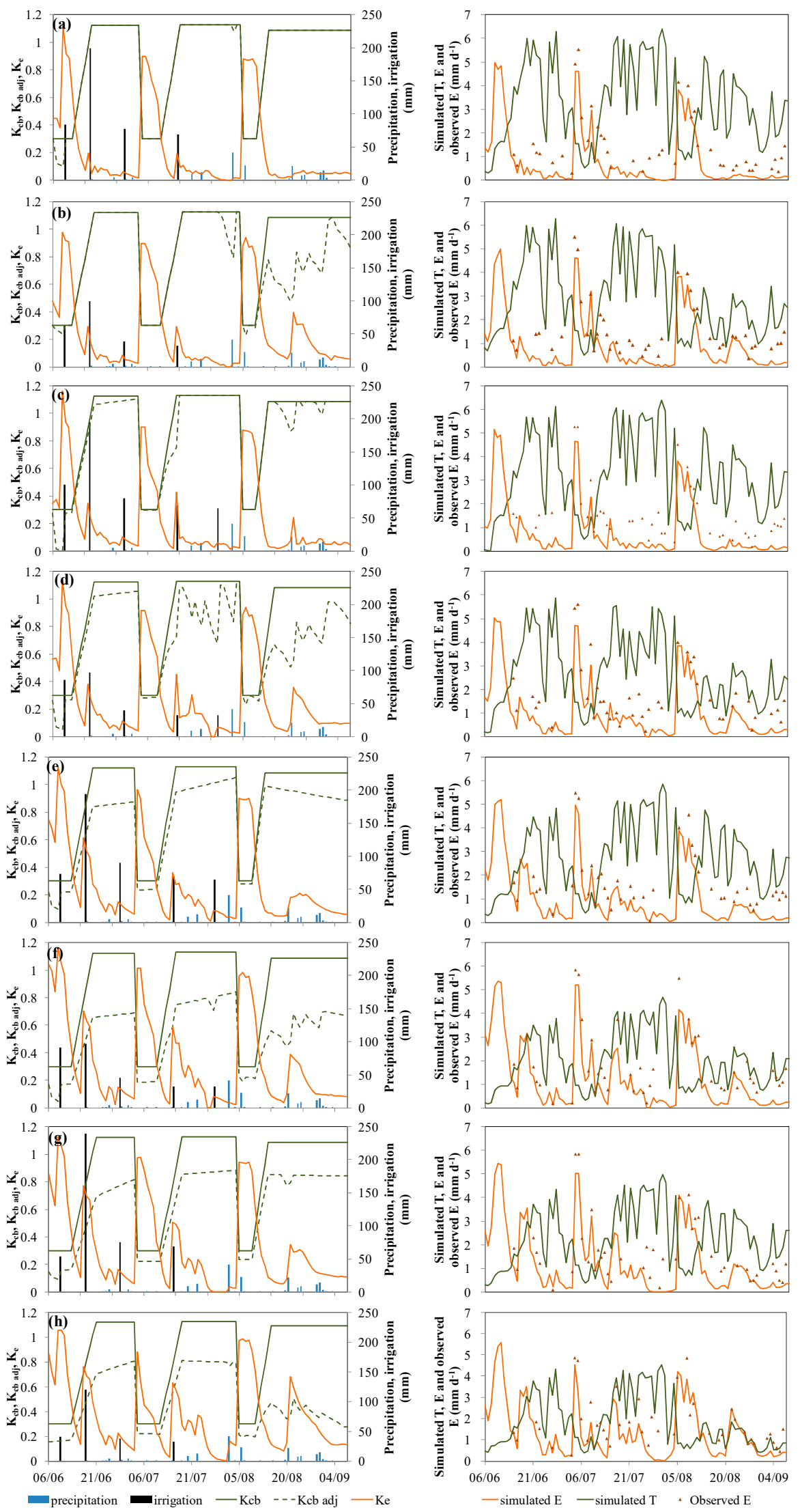

Figure 4. Seasonal variations of soil evaporation coefficient $\left(K_{e}\right)$, basal crop coefficient $\left(K_{c b}\right)$, adjusted $K_{c b}\left(K_{c b a d j}\right)$, precipitation and irrigation during the whole growth period of alfalfa in 2018. On the right panel, the simulated crop transpiration $(T)$, soil evaporation $(E)$ and observed $E$ for the alfalfa were shown. (a)-(h): W1S0, W2S0, W1S2, W2S2, W1S4, W2S4, W1S6 and W2S6. 
Table 3. Indicators of goodness of fit of soil evaporation $(E)$ related to the SIMDualKc model validation for alfalfa.

\begin{tabular}{|c|c|c|c|c|c|c|c|}
\hline Year & Treatments & $b$ & $R^{2}$ & $R M S E\left(\mathrm{~mm}^{-1}\right)$ & $A A E\left(\mathrm{~mm} \mathrm{~d}^{-1}\right)$ & $E F$ & $d_{I A}$ \\
\hline \multirow[t]{8}{*}{2018} & W1S0 & 0.97 & 0.90 & 0.744 & 0.629 & 0.64 & 0.92 \\
\hline & W2S0 & 0.97 & 0.87 & 0.716 & 0.598 & 0.63 & 0.91 \\
\hline & W1S2 & 0.97 & 0.90 & 0.795 & 0.716 & 0.54 & 0.89 \\
\hline & W2S2 & 0.92 & 0.87 & 0.795 & 0.688 & 0.59 & 0.90 \\
\hline & W1S4 & 0.94 & 0.88 & 0.756 & 0.654 & 0.59 & 0.90 \\
\hline & W2S4 & 0.90 & 0.87 & 0.793 & 0.643 & 0.67 & 0.92 \\
\hline & W1S6 & 0.91 & 0.83 & 0.778 & 0.625 & 0.65 & 0.91 \\
\hline & W2S6 & 0.90 & 0.76 & 0.773 & 0.636 & 0.53 & 0.89 \\
\hline \multirow[t]{4}{*}{2019} & W1S0 & 0.99 & 0.90 & 0.651 & 0.583 & 0.53 & 0.90 \\
\hline & W2S2 & 1.00 & 0.89 & 0.748 & 0.669 & 0.40 & 0.87 \\
\hline & W2S4 & 1.07 & 0.87 & 0.769 & 0.664 & 0.39 & 0.88 \\
\hline & W2S6 & 1.09 & 0.82 & 0.777 & 0.641 & 0.39 & 0.88 \\
\hline \multirow[t]{3}{*}{$2019^{*}$} & W2S2 & 1.00 & 0.89 & 0.749 & 0.670 & 0.40 & 0.87 \\
\hline & W2S4 & 1.02 & 0.89 & 0.764 & 0.674 & 0.40 & 0.87 \\
\hline & W2S6 & 1.01 & 0.84 & 0.764 & 0.638 & 0.41 & 0.88 \\
\hline
\end{tabular}

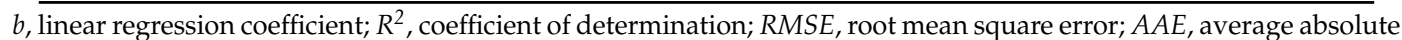
error; $E F$, the Nash and Sutcliffe modeling efficiency; and $d_{I A}$, Willmott index of agreement. Indicators of year in $2019^{*}$ were recomputed using dynamic yield response factor $\left(K_{y}\right)$.

However, the dual $\mathrm{K}_{\mathrm{c}}$ approach performed at reduced precision under water and salt stress. The simulations of SWC for treatments under stress were inferior to treatments for no stress, and the errors increased as stress was aggravated (Figure 3). Compared to full irrigation treatments, the differences between observed and simulated SWC under stress tended to increase, with an overestimation when SWC was low and an underestimation when SWC was high, especially the late stage of each cutting (e.g., Figure $3 b, d, e, g)$. The more severe the stress, the worse the simulation, e.g., W2S6. Simulated $E$ under no stress showed a relative better consistency with observations, whereas $E$ under stress presented larger biases along the growth period (Figure 4). Furthermore, simulation precision of $E$ under stress reduced, with the $R^{2}$ for W1S0, W2S4 and W2S6 were $0.90,0.87$ and 0.76, respectively. Larger differences appeared in the middle and late seasons of each cutting (Figure 4). One of reasons was that the dual $\mathrm{K}_{\mathrm{c}}$ approach or SIMDualKc model merely took the effect of short-term soil water deficit on $K_{c}$ into consideration, and water stress was considered to be released as soon as alfalfa was rewatered. However, the physiological and growth damage caused by long-time water stress was neglected, which cannot recover to the status before stress [26]. In addition, long-term salt stress would affect crop growth and water use process. Effects of salt stress were calculated through $E C_{e \text { threshold }}, b$ and $K_{y}$, which were considered constant under different stress levels, and may be unreasonable. Actually, these parameters were also related to specific crop growth environment and stages. When dynamic $K_{y}$ values were used in the simulation under stress, model performance was improved, and this would be further discussed in next section.

\subsection{Evaluation of the Effect of Dynamic $K_{y}$ on $E T$}

As known from the above section, the SIMDualKc model was able to better explain and predict $S W C$ and $E$ without water and salt stress. However, the model performed at reduced accuracy under water and salt stress, and the deviations between simulations and observations tended to increase as water and salt stress increased. The difference might be partly attributed to the constant $K_{y}$. In order to evaluate the effect of $K_{y}$ on simulations, we recomputed $K_{y}$ of different treatments in 2018 using simulated ET and corresponding measured yield by Equation (5) for 2018 (Table 4), and the updated $K_{y}$ was used in the simulation in 2019, which dynamically increased with the increased degree of stress. 
The simulations of the $S W C$ showed improved accuracy with recomputed dynamic $K_{y}$, compared to the constant $K_{y}$ ( $n=72$ for each treatment; Figure 5). According to indicators of goodness-of-fit shown in Table 2, the $R^{2}$ increased from $0.72-0.81$ to $0.82-0.83$, the RMSE decreased from $0.014-0.020$ to $0.013-0.014 \mathrm{~m}^{3} \mathrm{~m}^{-3}$ and the $E F$ increased from $0.61-0.78$ to $0.77-0.82$ for treatments under stress. The improved slope between simulated and measured SWC indicated that a better simulation of $E T$ under stress using the dynamic $K_{y}$. Simulated crop T, $E$ and observed $E$ for the alfalfa were shown in Figure 6. The $R^{2}$ increased from $0.82-0.89$ to $0.84-0.89$, the RMSE decreased from $0.748-0.777$ to $0.749-0.764 \mathrm{~mm} \mathrm{~d}^{-1}$ and the $E F$ increased from $0.39-0.40$ to $0.40-0.41$ for treatments under stress using the dynamic $K_{y}$ (Table 3). The differences between the simulated and observed $E$ decreased, indicating a better model performance with dynamic $K_{y}$.
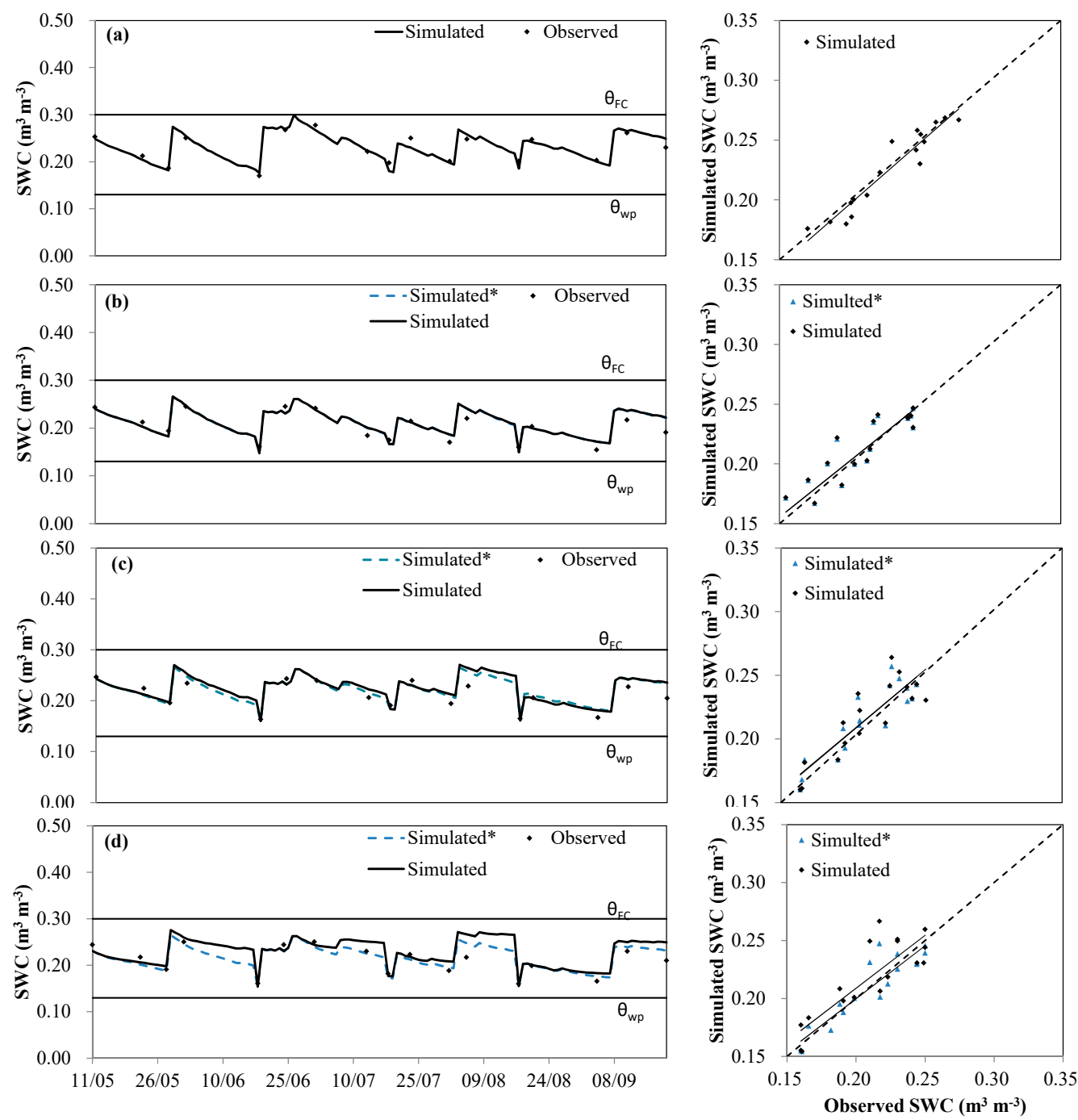

Figure 5. Simulated and observed soil water content $(S W C)$ during the whole growth period of alfalfa in 2019: (a) W1S0, (b) W2S2, (c) W2S4 and (d) W2S6. The simulations with a constant yield response factor $\left(K_{y}=1.2\right)$ were shown by solid lines and dynamic $K_{y}$ by dotted lines. On the right panel, the corresponding regressions forced to the origin were shown, and simulations with recomputed $K_{y}$ were shown with the asterisk $\left(^{*}\right)$. 
Table 4. The recalculated water-yield response factor $\left(K_{y}\right)$ of alfalfa using simulated evapotranspiration $(E T)$ and measured hay yield $\left(Y_{a}\right)$ in 2018.

\begin{tabular}{cccc}
\hline Treatments & $\boldsymbol{E T} \mathbf{( \mathbf { m m } )}$ & $\left.\boldsymbol{Y}_{\boldsymbol{a}} \mathbf{( \mathbf { k g ~ h a }} \mathbf{~}^{\mathbf{1}}\right)$ & $\boldsymbol{K}_{\boldsymbol{y}}$ \\
\hline W1S0 & 383 & 19979 & 1.20 \\
W2S0 & 361 & 18579 & 1.23 \\
W1S2 & 376 & 19530 & 1.23 \\
W2S2 & 344 & 17219 & 1.37 \\
W1S4 & 354 & 17881 & 1.42 \\
W2S4 & 304 & 13463 & 1.60 \\
W1S6 & 332 & 15810 & 1.60 \\
W2S6 & 301 & 12009 & 1.87 \\
\hline
\end{tabular}
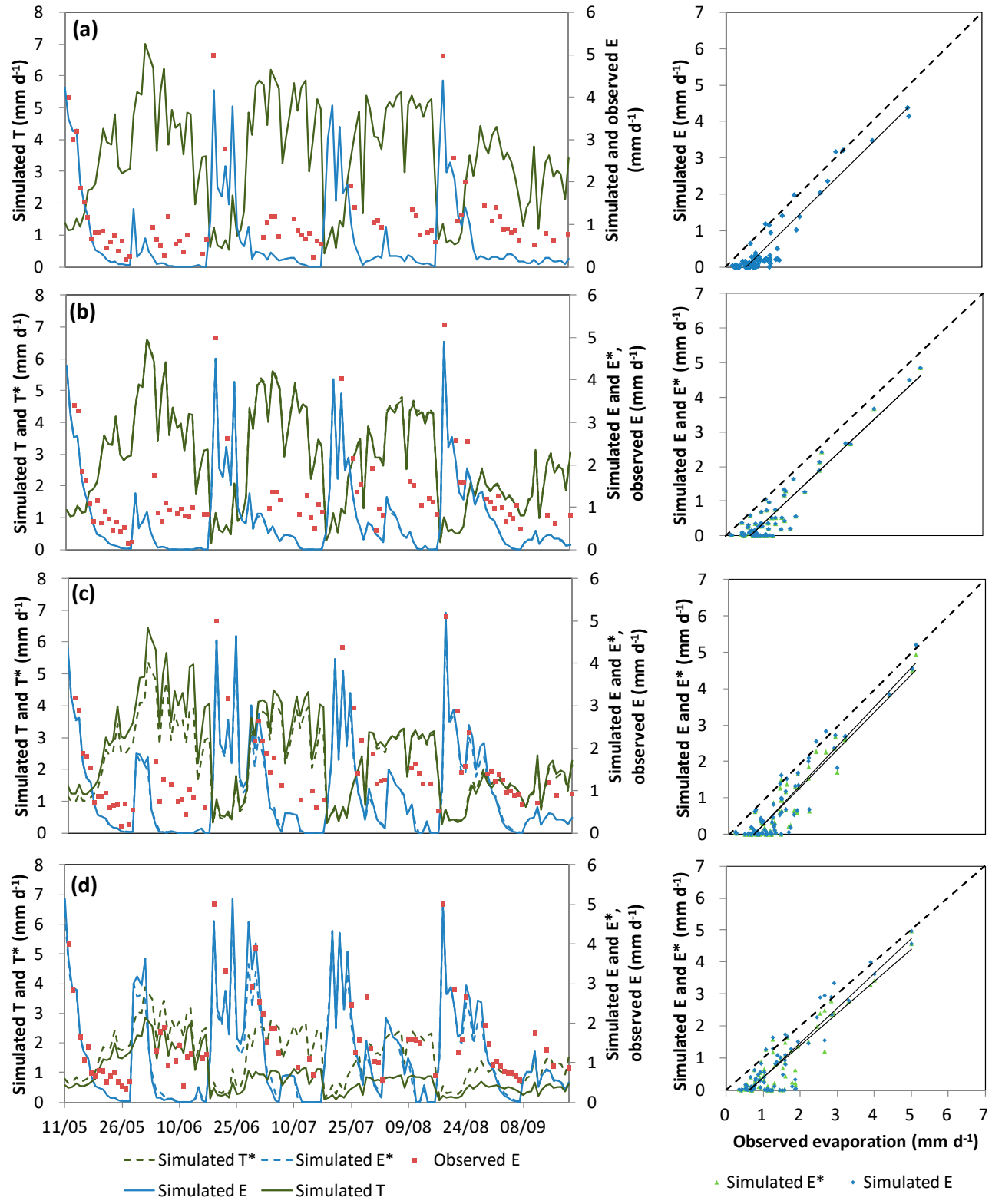

Figure 6. Simulated crop transpiration $(T)$, soil evaporation $(E)$ and observed $E$ for the alfalfa were shown during the whole growth period of alfalfa in 2019: (a) W1S0, (b) W2S2, (c) W2S4 and (d) W2S6. The simulations with a constant yield response factor $\left(K_{y}=1.2\right)$ were shown by solid lines and dynamic $K_{y}$ by dotted lines. 
The $K_{y}$ is a crop-specific factor that describes the reduction in relative yield according to the reduction in $E T$ caused by abiotic stress [5], and may vary over the crop season and different growth environments. The $K_{y}$ reflects the sensitivity of crop yield to stress, with higher value being higher sensitivity, i.e., greater reduction of stress on crop yield [5]. As shown in Table $4, K_{y}$ increased with aggravated water and salt stress, indicating greater reduction of yield under water and salt stress. Previous studies indicated that the combination of two or more stresses would result in more yield reduction than single factor $[27,29]$. Salt stress would both reduce the osmotic potential and increase ions toxic damage to crops [49]. Under saline conditions, many plants increase the concentration of body fluids to compensate for the lower soil water osmotic pressure by consuming certain metabolic energy [5]. Hence, crop growth under saline conditions slows down, resulting in the decrease of ground coverage and transpiration [50]. Our results indicated that reduction of yield was greater than that of ET under water and salt stress, leading to an increased $K_{y}$ (Table 4). These results suggested that the relationship between relative reductions of yield and $E T$ is nonlinear under different water and salt stress, which is different from the linear function in Equation (5). The slope between simulated and measured $E$ was closer to 1.0 under water and salt stress when the dynamic $K_{y}$ was used, which was better than constant $K_{y}$ (Figure 6 and Table 4). Combining with improved simulation of $S W C$, we concluded that diversity of $K_{y}$ for different stress is of great use to quantify the crop tolerance to stress and to better direct irrigation scheduling. Hence, the response and acclimation to stress should be incorporated into the model to improve the accuracy and precision of the model simulation $[26,40]$.

Our results indicated that the reduction of alfalfa yield was disproportionate with that of $E T$ under water and salt stress, leading to a variable $K_{y}$. So, dynamic or variable $K_{y}$ should be incorporated when making irrigation scheduling under water and salt stress. Although the use of dynamic $K_{y}$ increases the complexity of the application of dual crop coefficient method, it is worthwhile for efficient water use and precision irrigation management in water scarce regions, especially, under water and salt stress.

\section{Conclusions}

The dual $\mathrm{K}_{\mathrm{c}}$ model could satisfactorily estimate ET and components of alfalfa under water and salt stress (soil salt content $\leq 6 \%$ ) by using parameters suitable for alfalfa in an arid region of Northwest China. The $p$ and $b$ were slightly lower than those in the FAO-56, indicating that alfalfa had a lower capacity of water use but a greater tolerance to salt stress after reaching the salt threshold. However, the dual $\mathrm{K}_{\mathrm{c}}$ approach performed a reduced precision under water and salt stress. The key parameter $K_{y}$ dynamically increased with increased water and salt stress. The accessibility of a quantitative water-yield relationship is of great significance to improve the model performance, an easier way is to establish the relationship between $K_{y}$ and $L A I$, etc., and the relationship can vary when crop cultivar and management changed. Compared to the constant $K_{y}$, the simulations of SWC and $E$ showed improved accuracy with dynamic $K_{y}$. The response and acclimation of alfalfa to stress might be incorporated into the dual $K_{c}$ model through the diversity of $K_{y}$.

Supplementary Materials: The following are available online at http://www.mdpi.com/2073-4441/12/5/1224/s1, Table S1: Soil physical properties in the lysimeters. Table S2: Applied irrigation water depths and dates for the different treatments in 2018. Table S3: Applied irrigation water depths and dates for the different treatments in 2019. Table S4: Alfalfa growth stages and cutting dates for the different treatments in 2018. Table S5: Alfalfa growth stages and cutting dates for the different treatments in 2019. Table S6: Main crop parameters for the different treatments in 2018. Table S7: Main crop parameters for the different treatments in 2019.

Author Contributions: Experiment design: Y.H. and S.K. Data analysis: Y.H. and R.D. Contributed reagents/materials/analysis tools: S.K., R.D., T.D., L.T. and S.L. Manuscript writing: Y.H., S.K., R.D., T.D., L.T. and S.L. All authors have read and agreed to the published version of the manuscript.

Funding: This research was partially supported by the National Natural Science Foundation of China (51790534, 51679237, 51621061 and 51725904), and China Agriculture Research System (CARS-03-35).

Acknowledgments: The authors would like to express their gratitude for the funding agencies, the editor and reviewers for leveraging the quality of this work and students who participated in the fieldwork and laboratory work. 
Conflicts of Interest: The authors declare no conflict of interest.

\section{References}

1. Rengasamy, P. World salinization with emphasis on Australia. J. Exp. Bot. 2006, 57, 1017-1023. [CrossRef]

2. Singh, A. Poor-drainage-induced salinization of agricultural lands: Management through structural measures. Land Use Policy 2019, 82, 457-463. [CrossRef]

3. Lindenmayer, R.B.; Hansen, N.C.; Brummer, J.; Pritchett, J.G. Deficit irrigation of alfalfa for water-savings in the Great Plains and Intermountain West: A review and analysis of the literature. Agron. J. 2011, 103, 45-50. [CrossRef]

4. Schneekloth, J.; Andale, A. Seasonal Water Needs and Opportunities for Limited Irrigation for Colorado Crops. Colorado State University Extension, 2009. Available online: https://extension.colostate.edu (accessed on 24 April 2020).

5. Allen, R.G.; Pereira, L.S.; Raes, D.; Smith, M. Crop Evapotranspiration: Guidelines for Computing Crop Water Requirements; FAO Irrigation and Drainage Paper No.56; FAO-Food and Agriculture Organization of the United Nations: Rome, Italy, 1998; p. 300.

6. Cavero, J.; Faci, J.M.; Medina, E.T.; Martínez-Cob, A. Alfalfa forage production under solid-set sprinkler irrigation in a semiarid climate. Agric. Water Manag. 2017, 191, 184-192. [CrossRef]

7. Li, Y.; Su, D. Alfalfa water use and yield under different sprinkler irrigation regimes in north arid regions of China. Sustainability 2017, 9, 1-15.

8. Skaggs, T.H.; Poss, J.A.; Shouse, P.J.; Grieve, C.M. Irrigating forage crops with saline waters: 1. Volumetric lysimeter studies. Vadose Zone J. 2006, 5, 815-823. [CrossRef]

9. Cao, X.; Li, H.; Zheng, H.; Wang, J.; Feng, Y. Water consumption characteristic and water requirement calculation of alfalfa under different drip irrigation treatments. Water Sav. Irrig. 2016, 12, 15-19. (In Chinese with English abstract).

10. Greenwood, K.L.; Lawson, A.R.; Kelly, K.B. The water balance of irrigated forages in northern Victoria, Australia. Agric. Water Manag. 2009, 96, 847-858. [CrossRef]

11. Hunsaker, D.J.; Pinter, P.J., Jr.; Cai, H. Alfalfa basal crop coefficients for FAO-56 procedures in the desert regions of the southwestern US. Trans. ASAE 2002, 45, 1799-1815. [CrossRef]

12. Jensen, M.E.; Allen, R.G. Evolution of practical ET estimating methods. In Proceedings of the National Irrigation Symposium Decennial Symposium, Phoenix, AZ, USA, 14-16 November 2000.

13. Anapalli, S.S.; Ahuja, L.R.; Gowda, P.H.; Ma, L.; Marek, G.; Evett, S.R.; Howell, T.A. Simulation of crop evapotranspiration and crop coefficients with data in weighing lysimeters. Agric. Water Manag. 2016, 177, 274-283. [CrossRef]

14. Agam, N.; Evett, S.R.; Tolk, J.A.; Kustas, W.P.; Colaizzi, P.D.; Alfieri, J.G.; McKee, L.G.; Copeland, K.S.; Howell, T.A.; Chávez, J.L. Evaporative loss from irrigated interrows in a highly advective semi-arid agricultural area. Adv. Water Resour. 2012, 50, 20-30. [CrossRef]

15. Pereira, L.S.; Paredes, P.; Rodrigues, G.C.; Neves, M. Modeling malt barley water use and evapotranspiration partitioning in two contrasting rainfall years. Assessing AquaCrop and SIMDualKc models. Agric. Water Manag. 2015, 159, 239-254. [CrossRef]

16. Wei, Z.; Paredes, P.; Liu, Y.; Chi, W.W.; Pereira, L.S. Modelling transpiration, soil evaporation and yield prediction of soybean in North China Plain. Agric. Water Manag. 2015, 147, 43-53. [CrossRef]

17. Zhang, B.; Liu, Y.; Xu, D.; Zhao, N.; Lei, B.; Rosa, R.D.; Paredes, P.; Paço, T.A.; Pereira, L.S. The dual crop coefficient approach to estimate and partitioning evapotranspiration of the winter wheat-summer maize crop sequence in North China Plain. Irrig. Sci. 2013, 31, 1303-1316. [CrossRef]

18. Zhao, N.; Liu, Y.; Cai, J.; Paredes, P.; Rosa, R.D.; Pereira, L.S. Dual crop coefficient modelling applied to the winter wheat-summer maize crop sequence in North China Plain: Basal crop coefficients and soil evaporation component. Agric. Water Manag. 2013, 117, 93-105. [CrossRef]

19. Zhao, P.; Li, S.; Li, F.; Du, T.; Tong, L.; Kang, S. Comparison of dual crop coefficient method and Shuttleworth-Wallace model in evapotranspiration partitioning in a vineyard of northwest China. Agric. Water Manag. 2015, 160, 41-56. [CrossRef]

20. Allen, R.G.; Pereira, L.S. Estimating crop coefficients from fraction of groundcover and height. Irrig. Sci. 2009, 28, 17-34. [CrossRef] 
21. Howell, T.A.; Evett, S.R.; Tolk, J.A.; Schneider, A.D. Evapotranspiration of full-, deficit-irrigated, and dryland cotton on the northern Texas high plains. J. Irrig. Drain. Eng. 2004, 130, 277-285. [CrossRef]

22. Paco, T.A.; Ferreira, M.I.; Rosa, R.D.; Paredes, P.; Rodrigues, G.C.; Conceicao, N.; Pacheco, C.A.; Pereira, L.S. The dual crop coefficient approach using a density factor to simulate the evapotranspiration of a peach orchard: SIMDualKc model versus eddy covariance measurements. Irrig. Sci. 2012, 30, 115-126. [CrossRef]

23. Salarian, M.; Alizadeh, A.; Davary, K.; Ansari, H. The impact of water stress and salinity on water requirement and crop coefficient of greenhouse bell pepper. Adv. Environ. Biol. 2014, 8, 88-99.

24. Pereira, L.S. Water, agriculture and food: Challenges and issues. Water Resour. Manag. 2017, 31, $2985-2999$. [CrossRef]

25. Rosa, R.D.; Ramos, T.B.; Pereira, L.S. The dual Kc approach to assess maize and sweet sorghum transpiration and soil evaporation under saline conditions: Application of the SIMDualKc model. Agric. Water Manag. 2016, 177, 77-94. [CrossRef]

26. Ran, H.; Kang, S.; Li, F.; Tong, L.; Ding, R.; Du, T.; Li, S.; Zhang, X. Performance of AquaCrop and SIMDualKc models in evapotranspiration partitioning on full and deficit irrigated maize for seed production under plastic film-mulch in an arid region of China. Agric. Syst. 2017, 151, 20-32. [CrossRef]

27. Abdelraheem, A.; Esmaeili, N.; O'Connell, M.; Zhang, J. Progress and perspective on drought and salt stress tolerance in cotton. Ind. Crop. Prod. 2019, 130, 118-129. [CrossRef]

28. Farooq, M.; Hussain, M.; Wakeel, A.; Siddique, K.H.M. Salt stress in maize: Effects, resistance mechanisms, and management. A review. Agron. Sustain. Dev. 2015, 35, 461-481. [CrossRef]

29. Munns, R.; Tester, M. Mechanisms of salinity tolerance. Annu. Rev. Plant Biol. 2008, 59, 651-681. [CrossRef]

30. Ahmed, I.M.; Dai, H.; Zheng, W.; Cao, F.; Zhang, G.; Sun, D.; Wu, F. Genotypic differences in physiological characteristics in the tolerance to drought and salinity combined stress between Tibetan wild and cultivated barley. Plant Physiol. Biochem. 2013, 63, 49-60. [CrossRef]

31. Wang, Q.M.; Huo, Z.L.; Zhang, L.D.; Wang, J.H.; Zhao, Y. Impact of saline water irrigation on water use efficiency and soil salt accumulation for spring maize in arid regions of China. Agric. Water Manag. 2016, 163, 125-138. [CrossRef]

32. Yang, H.; Du, T.; Mao, X.; Ding, R.; Shukla, M.K. A comprehensive method of evaluating the impact of drought and salt stress on tomato growth and fruit quality based on EPIC growth model. Agric. Water Manag. 2019, 213, 116-127. [CrossRef]

33. Zhang, H.; Li, D.; Zhou, Z.; Zahoor, R.; Chen, B.; Meng, Y. Soil water and salt affect cotton (Gossypium hirsutum L.) photosynthesis, yield and fiber quality in coastal saline soil. Agric. Water Manag. 2017, 187, 112-121. [CrossRef]

34. Minhas, P.S.; Ramos, T.B.; Ben-Gal, A.; Pereira, L.S. Coping with salinity in irrigated agriculture: Crop evapotranspiration and water management issues. Agric. Water Manag. 2020, 227, 105832. [CrossRef]

35. Paredes, P.; Wei, Z.; Liu, Y.; Xu, D.; Xin, Y.; Zhang, B.; Pereira, L.S. Performance assessment of the FAO AquaCrop model for soil water, soil evaporation, biomass and yield of soybeans in North China Plain. Agric. Water Manag. 2015, 152, 57-71. [CrossRef]

36. Paredes, P.; D'Agostino, D.; Assif, M.; Todorovic, M.; Pereira, L.S. Assessing potato transpiration, yield and water productivity under various water regimes and planting dates using the FAO dual Kc approach. Agric. Water Manag. 2018, 195, 11-24. [CrossRef]

37. Yuan, C.; Feng, S.; Huo, Z.; Ji, Q. Effects of deficit irrigation with saline water on soil water-salt distribution and water use efficiency of maize for seed production in arid Northwest China. Agric. Water Manag. 2019, 212, 424-432. [CrossRef]

38. Hu, M.; Kang, S.; Zhang, J.; Li, F.; Du, T.; Tong, L. Potential use of saline water for irrigating shelterbelt plants in the arid region. Irrig. Drain. 2012, 61, 107-115. [CrossRef]

39. Jiang, J.; Huo, Z.; Feng, S.; Zhang, C. Effect of irrigation amount and water salinity on water consumption and water productivity of spring wheat in Northwest China. Field Crop. Res. 2012, 137, 78-88. [CrossRef]

40. Rosa, R.D.; Paredes, P.; Rodrigues, G.C.; Fernando, R.M.; Alves, I.; Pereira, L.S.; Allen, R.G. Implementing the dual crop coefficient approach in interactive software: 2. Model testing. Agric. Water Manag. 2012, 103, $62-77$. [CrossRef]

41. Ding, R.; Kang, S.; Zhang, Y.; Hao, X.; Tong, L.; Du, T. Partitioning evapotranspiration into soil evaporation and transpiration using a modified dual crop coefficient model in irrigated maize field with ground-mulching. Agric. Water Manag. 2013, 127, 85-96. [CrossRef] 
42. Allen, R.G.; Pereira, L.S.; Smith, M.; Raes, D.; Wright, J.L. FAO-56 dual crop coefficient method for estimating evaporation from soil and application extensions. J. Irrig. Drain. Eng. 2005, 131, 2-13. [CrossRef]

43. Liu, Y.; Pereira, L.S.; Fernando, R.M. Fluxes through the bottom boundary of the root zone in silty soils: Parametric approaches to estimate groundwater contribution and percolation. Agric. Water Manag. 2006, 84, 27-40. [CrossRef]

44. Paredes, P.; Pereira, L.S.; Rodrigues, G.C.; Botelho, N.; Torres, M.O. Using the FAO dual crop coefficient approach to model water use and productivity of processing pea (Pisum sativum L.) as influenced by irrigation strategies. Agric. Water Manag. 2017, 189, 5-18. [CrossRef]

45. Xu, C.; Liu, H.; Zhao, L. Calculating alfalfa irrigation quota by FAO Penman-Monteith equation. Trans. CSAE 2005, 21, 30-34, (In Chinese with English abstract).

46. Tao, X.; Su, D.; Kou, D.; Qiao, Y. Effects of irrigation methods on growth and water use efficiency of alfalfa in arid northwest China. Acta Agrestia Sinica 2016, 24, 114-120, (In Chinese with English abstract).

47. Qassim, A.; Dunin, F.; Bethune, M. Water balance of centre pivot irrigated pasture in northern Victoria, Australia. Agric. Water Manag. 2008, 95, 566-574. [CrossRef]

48. Jiang, X.; Kang, S.; Tong, L.; Li, F.; Li, D.; Ding, R.; Qiu, R. Crop coefficient and evapotranspiration of grain maize modified by planting density in an arid region of northwest China. Agric. Water Manag. 2014, 142, 135-143. [CrossRef]

49. Lovelli, S.; Perniola, M.; Ferrara, A.; Di Tommaso, T. Yield response factor to water (Ky) and water use efficiency of Carthamus tinctorius L. and Solanum melongena L. Agric. Water Manag. 2007, 92, 73-80. [CrossRef]

50. Saeidi, R.; Sotoodehnia, A.; Etedali, H.R.; Nazari, B.; Kaviani, A. Effect of water salinity and soil nitrogen deficiency on Ks-coefficient and readily available water of maize. J. Water Soil 2018, 32, 865-878.

(C) 2020 by the authors. Licensee MDPI, Basel, Switzerland. This article is an open access article distributed under the terms and conditions of the Creative Commons Attribution (CC BY) license (http://creativecommons.org/licenses/by/4.0/). 